\title{
Aligning Library Strategy and Structure With the Campus Academic Plan: A Case Study
}

Brinley Franklin

University of Connecticut, brinley.franklin@uconn.edu

Follow this and additional works at: https://opencommons.uconn.edu/libr_pubs

\section{Recommended Citation}

Franklin, Brinley, "Aligning Library Strategy and Structure With the Campus Academic Plan: A Case Study" (2009). Published Works. 20.

https://opencommons.uconn.edu/libr_pubs/20 


\title{
Aligning Library Strategy and Structure With the Campus Academic Plan: A Case Study
}

\author{
Brinley Franklin
}

\begin{abstract}
Colleges and universities' missions are typically comprised of educating students, training professionals, engaging in scholarship and research, promoting creative activity, improving healthcare, and providing public service. Academic libraries exist to support these core functions, yet most academic libraries are organized based on library functions rather than the primary missions of their college or university. This paper describes one academic library's attempt to align library strategy and structure with its university's academic plan.
\end{abstract}

KEYWORDS. Academic libraries, strategic planning, organization structure, reorganization

\section{INTRODUCTION}

Andrew Dillon, Dean of the School of Information at the University of Texas, recently wrote that:

Academic libraries will survive as long as there are universities.

However, libraries cannot thrive without aligning their workings directly to the core mission of their host institutions. ${ }^{i}$

Academic libraries have always existed to support the principal missions of their college or university. Today, however, advances in information technology, the increased cost of higher education, an aging academic library workforce, and a serious economic downturn have all converged to challenge how libraries engage in their academic support work.

Deborah Jakubs reflects the plight of $21^{\text {st }}$ century academic libraries' when she writes:

...libraries must continue to prove their value to the university and demonstrate that the very significant investment made in the library is well directed and well spent, an investment not only in our buildings, staff, and collections, but also in the academic success of students and faculty. ${ }^{\text {ii }}$ 


\section{RETHINKING THE UCONN LIBRARIES' APPROACH TO SERVICE}

The University of Connecticut (UConn) Libraries reorganized in 1996 into seven functional areas: (1) Access Services (2) Administrative Services (3) Archives and Special Collections (4) Collections Services (5) Information Technology Services (6) Regional Campus Libraries and (7) Research and Information Services. Each functional area consisted of teams that performed the library functions it was responsible for. This team structure was influenced by 1990s organizational development thinking, perhaps characterized most strongly in academic libraries by the University of Arizona Library. ${ }^{\text {iii }}$

Over the ensuing years, each of these functional areas created its own subculture within the UConn Libraries. Although a significant amount of the Libraries' work was achieved by using cross-functional teams, the focus of many library staff was primarily concentrated on the workings and success of their functional areas and area teams rather than the success of the Libraries as a whole. At times, issues being discussed by the Libraries' staff seemed to be focused as much on the Libraries' internal workings as its services to users.

In addition, the Libraries had adopted a culture of assessment in 1996 and it established a tradition of planning and assessment. After early improvements in the UConn Libraries' LibQUAL+® and local user survey scores from 1996 to 2001, user satisfaction with library services started leveling off based on subsequent surveys in 2004, 2006, and 2008.

A series of events converged in 2008 to cause the Libraries to rethink its approach to services. Powerful search engines like Google had replaced the traditional reference desk and become library users' first choice when seeking information. Mass digitization and advanced resource sharing tools forced libraries to re-think their service delivery models. ${ }^{\text {iv }}$

Locally, the campus adopted a new Academic Plan aimed at moving UConn into the top ranks of American public universities. The Provost charged each academic unit with the task of quickly adapting its strategic plan to support the campus academic plan. An unexpectedly severe economic downturn in the financial services industry reduced the State of Connecticut's tax revenues and the Governor reduced the University's block grant by $5 \%$, or $\$ 18$ million. Two of the seven UConn Libraries' functional area heads retired in 2008 and one re-located.

Also in 2008, Shelley Phipps, a library organizational development consultant, reintroduced the UConn Libraries staff to the systems model of organizations. The origin of this approach is attributed to Dr. W. Edwards Deming and was included almost fifty years later in a contemporary management tool, The Leader's Handbook ${ }^{\mathrm{v}}$ (see Figure 1). 
Figure 1. Diagram Used by Dr. Deming at his Lectures in Japan in 1950

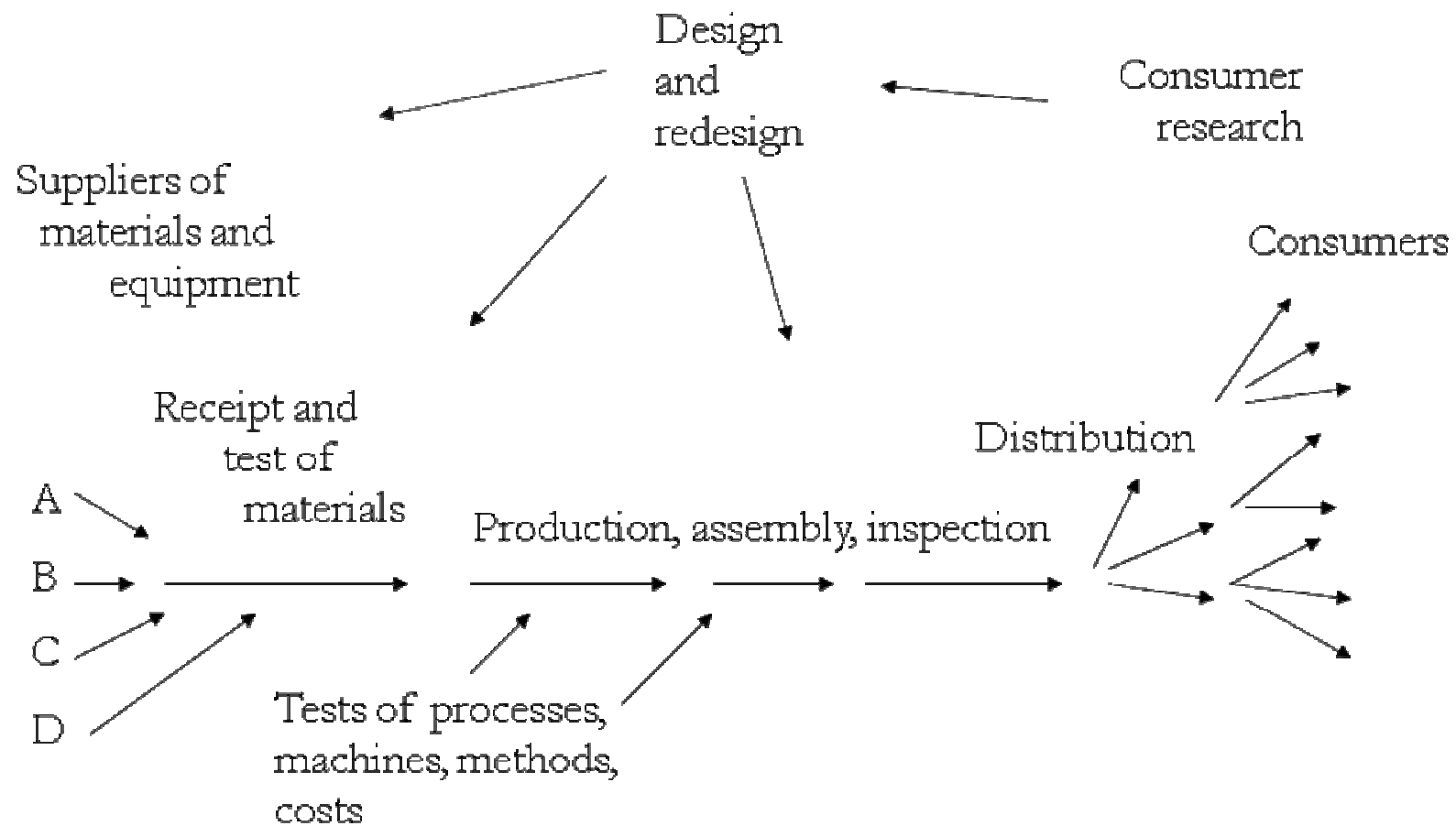

Dr. Deming's original diagram had evolved in the ensuing fifty years into the systems model of organizations that Shelley Phipps shared with us in 2008 (see Figure 2). In this context, the UConn Libraries had not been effectively using the feedback it was receiving from its customers to redesign its work processes in ways that would improve outcomes and help the Libraries to best achieve its mission and vision. Instead, the Libraries had become overly focused on contributing factors like its people, competencies, resources, structures, systems, culture, and climate.

The Burnham Rosen Group, a leadership and organizational development consulting firm, advised the Libraries' leadership team to refocus library staff on the Libraries' work processes as they related to customer service. In the words of Peter Drucker, "Neither results nor resources exist inside the business. Both exist outside. The customer is the business."

Another way of saying this was expressed by Donna Fitch, Jean Thomason, and Elizabeth Crabtree Wells:

How do you turn a library upside down and have it land on its feet? Facing the challenge of improving user services and staff morale, the professional staff of the Harwell G. Davis Library of Samford University answered this question by completely rethinking the physical and philosophical foundations of library 
operations. The resulting organization has been able to meet the challenge of service excellence with flexibility, enthusiasm, and efficiency. ${ }^{\text {vii }}$

Figure 2. The Systems Model of Organizations

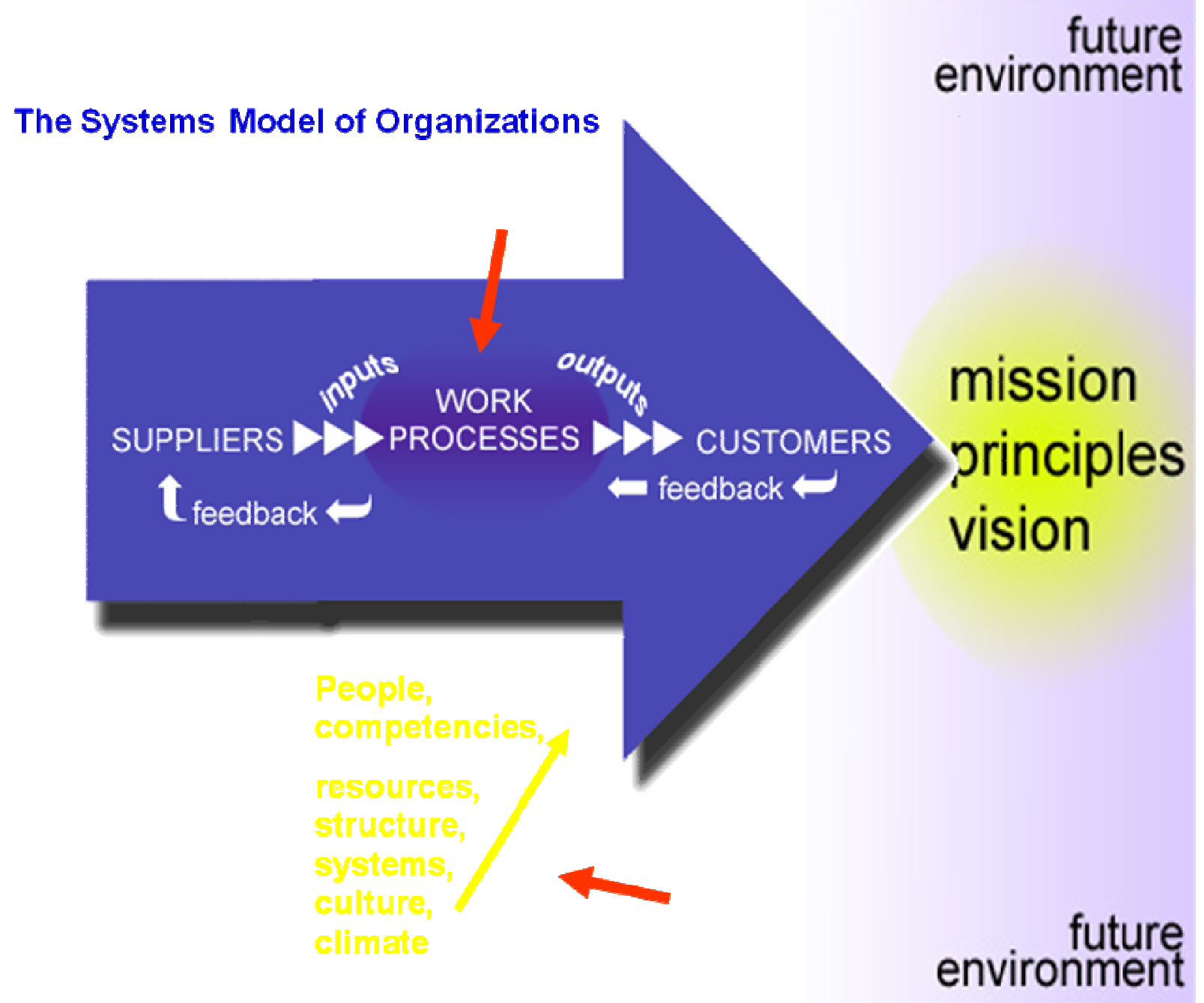

A strong theme in the work that Shelley Phipps and Chad Rosen undertook with the UConn Libraries related to refocusing on the Libraries' core mission of serving users. The Libraries had devoted considerable energies to organizational assessment in recent years. While some organization development work remained to be done, in particular returning authority to staff and holding them accountable, the Libraries particularly needed greater focus on library services provided to faculty, students and public users. 


\section{THE UNIVERSITY'S ACADEMIC PLAN AND THE LIBRARIES' STRATEGIC PLAN}

A new President took office at the University of Connecticut in September, 2007. A significant part of the President's first year in office, in collaboration with the Provost, was devoted to finalizing the University's Academic Plan.

UConn's academic plan identifies three focused areas of excellence: (1) the environment; (2) health and human behavior; and (3) arts, culture, and society. It also calls for advancing UConn's standing in five interrelated areas: (1) Undergraduate Education; (2) Graduate and Professional Education; (3) Research, Scholarship, and Creative Activity; (4) Diversity; and (5) Public Engagement. Each of these five areas has a specific goal, followed by several strategies for achieving the goal. Finally, specific metrics are appended to assess the success of each of these five goals.

Our World, Our People, Our Future: The University of Connecticut Academic Plan 2009-2014 ${ }^{\text {viii }}$ was approved by the University's Board of Trustees in October, 2008. That same month, the Provost asked each academic unit to update its strategic plan to support the University's academic plan within a six month timeframe.

The Libraries' strategic planning team was charged to: (1) meet with university administrators to understand the implications of UConn's Academic Plan and how the Libraries could help the different units in Academic Affairs be more successful (2) coordinate environmental scans (3) engage library staff in reviewing and analyzing LibQUAL+ ${ }^{\circledR}$ data (4) gather staff comments and make modifications to the Libraries' mission and values statements (5) develop a new vision statement for the Libraries (6) present a preliminary draft of the new plan to library staff and the Provost's Library Advisory Committee for comments and (7) submit a revised library strategic plan to the Provost's Office by January, 2009.

The strategic planning team decided early in its work that the Libraries' new strategic plan should mirror the University's Academic Plan as much as possible. Consequently, the five interrelated areas in the Academic Plan were chosen as the framework for the Libraries' strategic plan. The Libraries' 2008 LibQUAL $+\circledR$ results were cross tabulated by discipline and academic liaison librarians, after training from ARL consultants, were charged with reviewing their 2008 LibQUAL+ ${ }^{\circledR}$ scores and then writing metrics for improving their user satisfaction scores. Based on input from its various stakeholders, the library strategic planning team wrote a goals statement, strategies, and metrics for each of the five areas in the Academic Plan. Illustrative examples follow:

\section{Undergraduate Education}

Goal - Actively support our undergraduates with intellectually challenging and diverse resources, continuous improvement in services, excellent learning environments, and opportunities to engage in critical thinking that adhere to information literacy standards. 
Strategy - Foster success in undergraduate education by enriching our instruction and outreach efforts to enhance students' information literacy skills.

Metric - Improve scores on library-wide undergraduate-focused qualitative assessments of information literacy.

\section{Graduate and Professional Education}

Goal - Enhance strategic graduate and professional programs through active library liaison engagement and resource support.

Strategy - Promote technology-enhanced individual and collaborative facilities within the Library to promote graduate school interactions and research on all campuses.

Metric - Increase perceived level of service quality for community space for group learning and group study from 6.87 in 2008 to 7.3 in 2014 (relates to LibQUAL+® question LP-5).

\section{Research, Scholarship, and Creative Activity}

Goal - Actively support faculty, student, and staff research, scholarship, and creative endeavors through quality instruction, liaison collaboration, collections, and information access.

Strategy - Enhance access to and awareness of research and publication at UConn.

Metric - Increase the number of items in the DigitalCommons@UConn.edu by $50 \%$, from 4,800 in 2009 to 7,200 by 2014 .

\section{Diversity}

Goal - Ensure an enriched learning and work environment by creating a more inclusive community that recognizes and celebrates individual differences.

Strategy - Strengthen programs that promote cultural competency among faculty, staff, and students.

Metric - Increase the number of public programs per year related to diversity by $50 \%$, from 4 to 6 .

\section{Public Engagement}

Goal - Enhance the contributions of UConn Libraries' staff to the state, nation, and world through public programming and appropriate collaboration with partners in the public and private sectors.

Strategy - Increase the utilization of library staff expertise in the State. Metric - Increase the number of annual consultancies to public sector organizations by $100 \%$, from 5 in 2009 to 10 in 2014 .

The Libraries' expect that focusing on these metrics related to user satisfaction and directing efforts towards priorities in the University's Academic Plan will underscore the value of UConn's investment in its Libraries. 


\section{ALIGNING THE LIBRARIES' STRUCTURE TO THE ACADEMIC PLAN}

The University of Connecticut Libraries Reorganization Project Team was charged with finalizing an organizational structure for the University of Connecticut Libraries within a framework provided by its Vice Provost that would shift the Libraries' focus from an organizational structure based on internal library functions to an organizational structure designed to support the University's Academic Plan.

A member of the Libraries' reorganization planning team, early in its work, shared copies of UConn's peer institutions libraries' organization charts. The eight peers are determined by the University's Office of Institutional Research. ${ }^{\text {ix }}$ With very few exceptions, these eight libraries' organizational structures were based on functional units with names like: access services; administrative services; collections, instruction, and public services; special collections and archives; technical services; research and instructional services; collection development and management; user services; and reference and instruction.

Some functional units had contemporary names like digital library services, scholarly communication, and information technology, but one might think that library organizational structures would have changed more substantively in recent years, given the rapid changes in the information environment.

As Sarah Pritchard describes,

In the digital environment, we still have resources, staff, and facilities that combine in various ways to acquire and provide information. These recombinations challenge traditional definitions of library organization. Library leaders and staff need to do this deconstruction so that stagnation does not set in, and we can incorporate new services and collections while still living within the same budgets and buildings. ${ }^{\mathrm{X}}$

Borrowing from an approach described to the author by Barbara Dewey, the strategic planning team began its work with an organizational framework already prescribed. The UConn Libraries framework consisted of five program areas that loosely corresponded to the University's academic plan goals:

1. Academic Research Services

2. Undergraduate Education and Access Services

3. The Thomas J. Dodd Research Center

4. The Regional Campus Libraries and

5. Central Services

The team focused most of its early discussions around the input it received from library staff, looking for common ideas and unique or innovative approaches it considered worthy of further discussion. As patterns began to develop, the team reached consensus on many elements of a new organization structure. Emerging decisions on placement of 
about half of the Libraries' 20 teams were tested at an all staff retreat and library staff discussed where to place the other half. After the retreat, the team decided upon four criteria for placing the remaining teams. These criteria were: (1) aligns with the acadmic plan goals and University structure (2) best serves our users or addresses user needs (3) promotes internal collaboration and de-silos the library and (4) positions the organization for the future. A fifth "unofficial" criterion, "does this work in real life?" was also utilized by the team to determine if certain aspects of its recommended plan made operational as well as organizational sense.

The final organizational structure, reflecting the placement of the Libraries' 20 teams in the five program areas is reflected in Figure 3.

Figure 3. The University of Connecticut Libraries Organization Chart, 2009

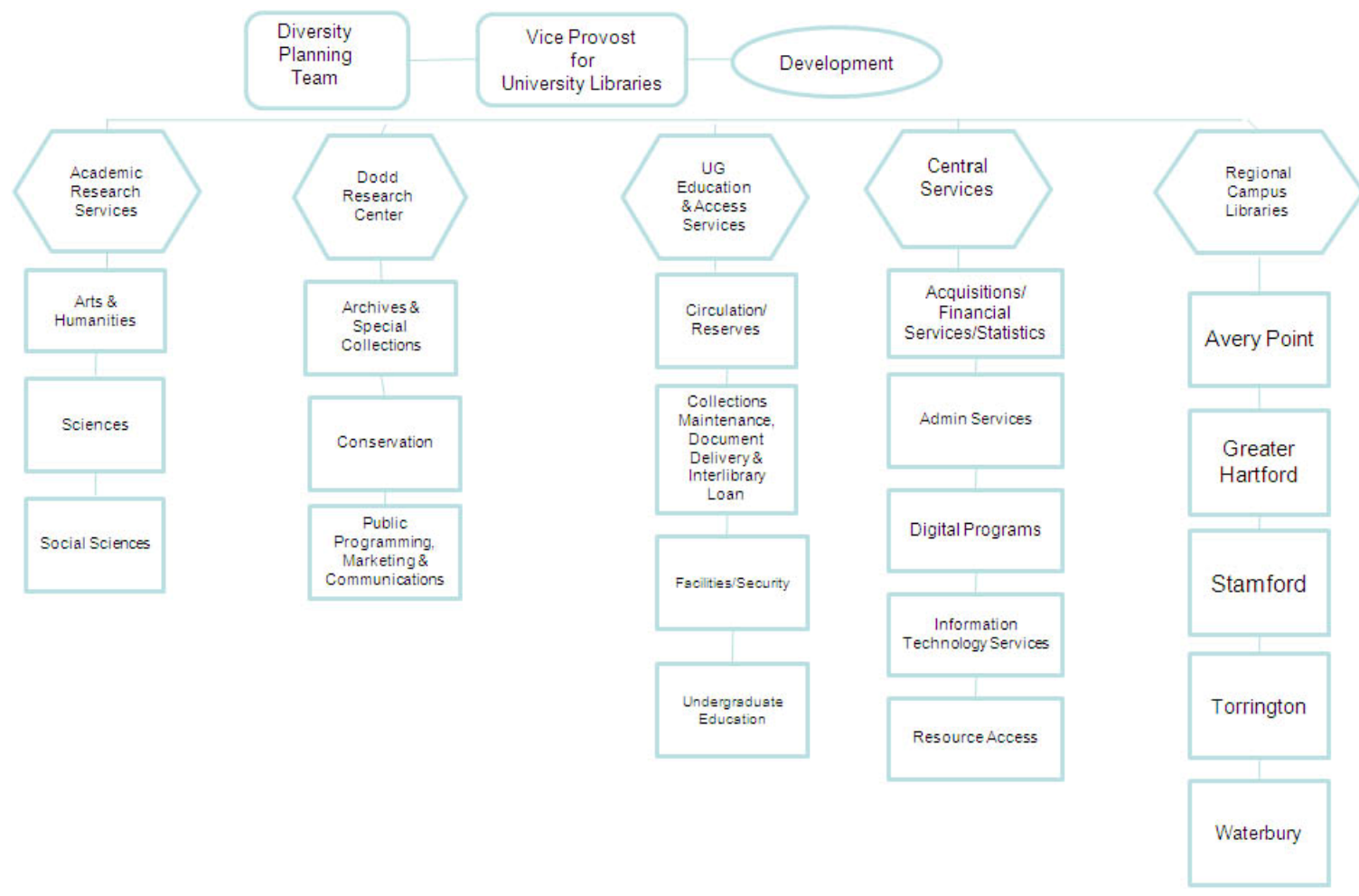

The Libraries' development efforts and a cross-program team, the Diversity Planning Team, report directly to the Vice Provost for University Libraries. Each academic unit at UConn is required to submit an annual diversity plan to the Provost's Office and the Libraries' Reorganization Planning Team understood that all library staff have a responsibility for promoting diversity on campus. 
In this new organizational structure, alignment with the five goals in the University's Academic Plan is reflected by:

1. Academic Research Services having primary responsibility for Graduate and Professional Education and Research, Scholarship, and Creative Activity.

2. The Dodd Research Center assuming primary responsibility for Public Engagement.

3. Undergraduate Education and Access Service having primary responsibility for Undergraduate Education.

4. The Diversity Planning Team assuming primary responsibility for coordinating the Libraries' efforts related to Diversity.

Per the Libraries strategic plan, Central Services is charged with engineering process improvements and reallocating staff to support the University's academic plan and directly serve UConn undergraduate students, graduate and professional students, faculty, and staff.

The Regional Campus Libraries are in effect microcosms of the Libraries' operations at its main campus, primarily serving undergraduate students and graduate programs in business, social work, and marine sciences. The Regional Campus Libraries staff members have secondary reporting relationships to either the discipline-based teams in Academic Research Services or Undergraduate Education and Access Services. Regional Campus Libraries staff members are also expected to participate in Public Engagement and to promote diversity.

Progress toward completing these planning efforts will be measured during the next five years by the metrics in the Libraries' strategic plan. Interim user surveys will be conducted and an independent review team will perform a program review midway through the plan's time span to help determine if the Libraries are making satisfactory progress towards achieving its goals. The ultimate test of success will be how well integrated the UConn Libraries have become in the University's efforts to carry out its Academic Plan and if the Libraries' user survey results and LibQUAL+ ${ }^{\circledR}$ scores reflect greater user satisfaction in 2014.

Brinley Franklin is Vice Provost, University of Connecticut Libraries, Storrs, CT 06269-2005 (Email: Brinley.franklin@uconn.edu)

The author wishes to acknowledge: Strategic Planning Team members JoAnn Reynolds, Valerie Love, Carolyn Mills, and Shelley Roseman and Reorganization Planning Team members Francine DeFranco, Nancy Dryden, Kristin Eshelman, Marian Farley, Scott Kennedy, Jill Livingston, Betsy Pittman, William Uricchio and Barbara Cervera. The author also wants to thank Richard Bleiler and Raynna Bowlby for their research and editorial assistance. 


\section{NOTES}

${ }^{i}$ Dillon, Andrew, "Accelerating Learning and Discovery: Refining the Role of Academic Librarians." In No Brief Candle: Reconceiving Research Libraries for the $21^{\text {st }}$ Century (Washington, DC: Council on Library and Information Resources, 2008), p.57.

ii Jakubs, Deborah, "Out of the Gray Times: Leading Libraries into the Digital Future," Journal of Library Administration 48, 2 (May, 2008), p. 238

iii See, for example, Joseph Diaz and Chestalene Pintozzi, Helping Teams Work: Lessons Learned from the University of Arizona Library Reorganization," Library Administration and Management 13,1 (Winter, 1999), pp. 27-36.

${ }^{\text {iv }}$ See, for example, David Lewis, "A Strategy for Academic Libraries in the First Quarter of the $21^{\text {st }}$

Century, College \&Research Libraries. http://idea.iupui.edu/dspace/handle/1805/1592

${ }^{v}$ Scholtes, Peter R. The Leader's Handbook (New York: McGraw-Hill, 1998), p. 8.

${ }^{\mathrm{vi}}$ Drucker, Peter, Managing for Results (New York:Harper \& Row, 1964), p. 5.

${ }^{v i i}$ Fitch, Donna K., Jean Thomason, and Elizabeth Crabtree Wells, "Turning the Library Upside Down: Reorganization Using Total Quality Management Principles," The Journal of Academic Librarianship 19,5 (November, 1993), p. 294.

viii http://academicplan.uconn.edu/

${ }^{i x}$ UConn's current peer institutions are identified by its Office of Institutional Research as: Iowa State University, Ohio State University, Purdue University, Rutgers University, the University of Georgia, The University of Iowa, the University of Minnesota, the University of Missouri,

${ }^{x}$ Pritchard, Sarah M., "Deconstructing the Library: Reconceptualizing Collections, Spaces and Services." Journal of Library Administration 48(2) (May, 2008), pp. 219 and 232. 